\title{
Leitura imagética de um curta-metragem: o uso das novas tecnologias no ensino de língua inglesa
}

\author{
Lectura de imágenes de un cortometraje: el uso de nuevas \\ tecnologías en la enseñanza de la lengua inglesa
}

\author{
Imagery reading of a short film: the use of new \\ technologies in the English language teaching
}

\author{
Marileuza Ascencio Miquelante* \\ Marilice Zavagli Marson* \\ Priscila Azevedo da Fonseca Lanferdini*
}

\begin{abstract}
RESUMO: A sociedade contemporânea tem sido marcada pela intensa produção e circulação de diferentes textos multissemióticos/multimodais e pelo uso de diversas mídias de comunicação. Neste contexto, a escola, historicamente influenciada por uma cultura grafocêntrica, vem sendo convocada a repensar suas práticas de letramento. Assim, buscando alternativas que possam contribuir na construção de um currículo multiletrado, apresentamos, neste trabalho, uma proposta didática para o ensino de Língua Inglesa por meio da leitura imagética de um curta-metragem. Para tanto, partimos de sugestões pedagógicas ancoradas na teoria enunciativo-discursiva do Círculo de Bakhtin, bem como em reflexões teóricas acerca de trabalhos com textos multimodais. Esperamos que nossa proposta possa ajudar/inspirar professores de línguas a pensarem em práticas de letramento favoráveis à formação cidadã de seus estudantes em um mundo globalizado.
\end{abstract}

PALAVRAS-CHAVE: Curta-metragem. Proposta didática. Multimodalidade.

RESUMEN: La sociedad contenporánea ha sido marcada por la intensa producción y circulación de diferentes textos multi-semióticos/multimodalidades, usados por diversos medios de comunicación. En este contexto, la escuela, históricamente influenciada por

*Doutoranda em Estudos da Linguagem pelo PPGEL - UEL - Programa de Estudos da Linguagem da Universidade Estadual de Londrina. Professora Assistente de Língua Inglesa na UNESPAR - Universidade Estadual do Paraná - campus Campo Mourão. mikelante@gmail.com

*Mestre em Estudos da Linguagem pelo PPGEL - UEL - Programa de Estudos da Linguagem da Universidade Estadual de Londrina. Professora Substituta de Língua Inglesa na UTFPR Universidade Tecnológica Federal do Paraná - campus Cornélio Procópio. marilicemarson@gmail.com

*Doutoranda em Estudos da Linguagem pelo PPGEL - UEL - Programa de Estudos da Linguagem da Universidade Estadual de Londrina. Professora Efetiva de Língua Inglesa da SEED - Secretaria de Estado da Educação - Núcleo Regional de Guarapuava. planferdini@yahoo.com.br 
una cultura "grafocêntrica", viene siendo llamada a repensar sus prácticas de alfabetización. De esta manera, se buscan alternativas que puedan contribuir en la construcción de un currículo letrado. Por tal motivo, presentamos en este trabajo, una propuesta didáctica para la enseñanza de la lengua inglesa, por medio de la lectura de las imágenes de un cortometraje. Para tal propósito, partimos de sugerencias pedagógicas ancladas a la teoría enunciativa-discursiva del Círculo de Bakhtin, además de reflexiones teóricas acerca de trabajos con textos multimodalidades. Esperamos que nuestra propuesta pueda ayudar e inspirar a professores de lenguas a pensar en prácticas de alfabetización favorables a la formación ciudadana de sus estudiantes en un mundo globalizado.

PALABRAS CLAVE: Cortometraje. Propuesta didáctica. Multimodalidad.

ABSTRACT: The modern society has been marked by the intense production and circulation of different multisemiotic/multimodal texts as well as by the use of many communication media. In that context, school, historically influenced by a grafocentric culture, has been called to rethink its literacy practices. Thus, as a way to offer alternatives that can contribute to the construction of a multiliterate school's curriculum, we present, in this paper, a didactic proposal for the English language teaching through a short film imagery reading. To do so, we start from pedagogical suggestions concerning Bakhtin's enunciative-discursive theory as well as theoretical reflections about multimodal texts works. We intend that our proposal can help/inspire language teachers to think about positive literacy practices to the citizen education of their students in a globalized world.

KEYWORDS: Short film. Didactic proposal. Multimodality.

\section{Introdução}

Vivemos hoje em uma era de aceleradas mudanças políticas, econômicas e sociais relacionadas à transformação dos recursos tecnológicos e seus impactos nas formas de interação humana. Diante de tal conjuntura, novos desafios se impõem à escola, na formação de indivíduos capazes de analisar criticamente a grande quantidade de informação que circula na sociedade, bem como de fazer o uso das novas práticas letradas em benefício próprio e do coletivo. Em prol de tal formação, na área de ensino e aprendizagem de línguas estrangeiras, acreditamos ser necessário o desenvolvimento de propostas de (multi)letramento que melhorem e/ou ampliem as capacidades de leitura e produção textual dos alunos. Nessa direção, Rojo e Moura (2013) nos alertam que 


\begin{abstract}
o que temos no Brasil hoje é um problema com os letramentos do alunado (e da população em geral). Não será o ensino de regras da língua, das estruturas dos textos, das formas dos gêneros ou das escolas literárias que poderá dar jeito nisso, mas sim eventos escolares de letramento que provoquem a inserção do alunado em práticas letradas contemporâneas, e com isso desenvolvam as competências/capacidades de leitura e escrita requeridas na atualidade [...] (ROJO; MOURA, 2013, p. 236).
\end{abstract}

Levando em conta tais necessidades, este artigo objetiva propor um trabalho de leitura imagética em torno do gênero discursivo ${ }^{1}$ curta-metragem, a fim de proporcionar possibilidades de ensino que envolvamos novos letramentos digitais e multissemióticos, assim como uma reflexão sobre os novos produtos culturais de nossa época.

Em face das dificuldades encontradas no ensino de Língua Inglesa (doravante LI) em relação ao desinteresse e à falta de motivação dos alunos para o aprendizado dessa língua, entendemos que um trabalho por meio do uso das novas tecnologias pode contribuir para o engajamento dos estudantes em práticas de uso da linguagem, tendo em vista a predisposição destes para a realização de atividades que contemplem recursos tecnológicos. A escolha do gênero ocorreu devido ao seu potencial em contribuir para que o aluno possa imergir em práticas sociais de uso da linguagem, assim como fazê-lo refletir sobre as possibilidades de produção cultural contemporânea e também sobre as representações e ideias veiculadas por tais produções.

A proposta didática aqui apresentada tem como base teórica e metodológica as sugestões pedagógicas de Rojo (2009), Rojo e Barbosa (2015), Rojo e Moura (2012, 2013), fundamentadas na teoria enunciativodiscursiva do Círculo de Bakhtin. Procuramos nos concentrar, especialmente, no desenvolvimento das capacidades de leitura de um texto multimodal (curtametragem), buscando explorar diferentes modos semióticos empregados no discurso, bem como suas funções na construção dos sentidos no texto, como defendido por Kress (2010). Para alcançar nossos objetivos, primeiramente, buscamos discutir a inserção das novas tecnologias nas práticas de

\footnotetext{
${ }^{1}$ Neste trabalho, optamos pelo uso do termo "gêneros discursivos" por coerência ao referencial teórico utilizado.
} 
(multi)letramento escolar. Em seguida, abordamos as questões relacionadas à análise multissemiótica no ensino de línguas e, por fim, apresentamos uma proposta didática para o trabalho com o gênero discursivo curta-metragem.

\section{As novas tecnologias e as práticas de (multi)letramentos na escola}

O desenvolvimento acelerado dos meios digitais tem sido sentido em todo o mundo, ainda que em proporções diferentes, tendo em vista o nível de desenvolvimento de cada sociedade e a ingerência de fatores políticos, econômicos, culturais, entre outros. A grande propagação de recursos tecnológicos tem feito com que as tecnologias digitais de informação e comunicação (TDIC) se integrem às mais diversas esferas de atividade humana, impactando nas formas de comunicar, ser e pensar das pessoas e no desenvolvimento econômico e social dos países. Deste modo, como afirma Castells (2000), as TDIC têm ocasionado mudanças na sociedade contemporânea que vão desde a reorganização do sistema capitalista (a fim de aumentar o acúmulo de capital), às transformações culturais das formas de relacionamento.

Nesse contexto, há de se considerar que os mesmos recursos que podem ser promotores de desenvolvimento parecem ter propiciado a ampliação das desigualdades sociais, visto que relevante parte da população mundial ainda se encontra desconectada do novo sistema tecnológico de comunicação (CASTELLS, 2000), como podemos observar pelo grande percentual de pessoas que ainda não possui acesso às TDIC em nosso país. Segundo relatório do IBGE$^{2}$, sobre o uso da internet no Brasil referente ao ano de 2013, apenas $48 \%$ dos domicílios brasileiros possuem acesso à internet $(88,4 \%$ por meio de microcomputador e $11,6 \%$ por meio de outros equipamentos). Ao analisar 0 uso da internet em relação ao rendimento mensal per capita das famílias brasileiras, o abismo parece ser ainda maior: nas famílias com rendimento de

2 Pesquisa Nacional por amostra de domicílios: Acesso à internet e à televisão e posse de telefone móvel celular para o uso pessoal. IBGE, 2013. Disponível em: <http://biblioteca.ibge.gov.br/visualizacao/livros/liv93373.pdf>. Acesso em: 29 set. 2015. 
10 ou mais salários mínimos per capita, foi observado que $89,9 \%$ das pessoas fizeram uso da internet no período de pesquisa, enquanto que para as famílias com rendimento de $1 / 4$ de salário mínimo per capita 23,9\% utilizaram.

Apesar da grande desigualdade apontada, no relatório também é possível observar uma crescente ampliação do acesso às TDIC nos anos de 2005, 2008 e 2013. Apesar de tal ampliação ser um aspecto positivo, outras implicações precisam ser consideradas: qual é a qualidade de participação social que se dá com a ampliação do acesso às TDIC? O mero acesso aos meios digitais possibilita aos sujeitos a participação em atividades sociais até então consideradas privilegiadas? A ampliação de acesso aos meios digitais tem possibilitado formas de articulação política e coletiva?

Segundo Rojo e Barbosa (2015), as TDIC, do modo como foram arquitetadas, configuradas e disseminadas, podem potencializar alguns processos pelos quais a sociedade contemporânea tem passado. Para as autoras, na hipermodernidade os grandes projetos coletivos vêm perdendo espaço; os partidos políticos, sindicatos e associações não têm mais o mesmo poder de mobilização do século passado. 0 mesmo acontece com as grandes ideologias que estão perdendo sua legitimidade e a força de convergência das pessoas em busca de um projeto social maior, prevalecendo a busca por interesses individuais. $\mathrm{O}$ distanciamento de ações ligadas a projetos políticos ou ideológicos consistentes faz com que os sujeitos se afastem da participação crítica, dando lugar ao consumo do que é veiculado pelas diferentes mídias de forma passiva e acrítica.

No que diz respeito à grande circulação de informações nos meios digitais, Rojo e Barbosa (2015) ressaltam que tais meios nos passam a ilusão aparente de que há fontes diversas de informações, no entanto, o que acontece é a redistribuição ou apropriação anônima destas. A partir disso, as autoras alertam que grande parte das informações consumidas continua sendo produzida e distribuída pelas mesmas agências de antes. A busca por outras fontes de informação requer do leitor proatividade, dependente de uma postura crítica por parte do sujeito, que se coloca para além de usuário. 
Dentro deste cenário, percebemos que a escola vem sendo chamada a repensar suas práticas pedagógicas, a fim de possibilitar e ampliar a qualidade das participações dos alunos em diferentes atividades de linguagem oportunizadas pelas TDIC. Esse é o tema central do texto seminal do New London Group, em que Cazden et al. (1996), há quase dez anos, advogaram que a pedagogia de letramentos precisa levar em conta uma variedade de textos relacionados às tecnologias de informação e a multimídia. Para os autores, o objetivo central da educação é possibilitar que todos os alunos se beneficiem da aprendizagem, de maneira a tornarem-se capazes de participar da vida pública, comunitária e econômica, sendo assim necessário o letramento em variadas formas de comunicação e mídia. Por isso, os autores defendem a ideia de "multiletramentos", palavra escolhida para descrever a grande variedade de canais de comunicação e mídia e a crescente diversidade cultural e linguística que vêm demandando diferentes formas de letramentos críticos.

Nessa mesma linha, Rojo (2009) entende que a escola precisa preocupar-se com o acesso dos alunos a espaços valorizados de cultura e que as práticas de letramento precisam ser revistas, pois têm apresentado resultados elitizados e não suficientes para a maior parte da população. Nesse sentido, a escola precisa possibilitar a participação dos alunos em diferentes práticas sociais que fazem uso da leitura e da escrita, de forma ética e democrática. Para tanto, a autora propõe que a educação linguística considere: os letramentos multissemióticos, os letramentos críticos e protagonistas e os letramentos múltiplos. A escola deve potencializar o diálogo multicultural, trazendo para a sala de aula a cultura valorizada e também as culturas locais, populares e a de massa. Para tanto, Rojo (2009) sugere que a partir do conceito de letramento, o professor organize um currículo pautado nas diferentes esferas de gêneros discursivos (BAKHTIN, 1992[1979]).

Apostando no trabalho a partir do conceito de gêneros discursivos, a autora tem publicado uma série de produções de caráter teórico-prático, articulando o conhecimento teórico e a prática pedagógica (ROJO; BARBOSA, 2015; ROJO; MOURA, 2012, 2013). A exemplo desses trabalhos, buscamos 
organizar a proposta didática aqui apresentada contemplando possibilidades para o letramento digital multissemiótico/multimodal. Para tanto, na próxima seção, discutimos questões relacionadas à multimodalidade e ao ensino de línguas.

\section{A multimodalidade no ensino e na aprendizagem de línguas}

Com a intensificação e o aceleramento da circulação de informação, os novos meios eletrônicos passaram a veicular diversos gêneros discursivos que articulam variados recursos semióticos, gêneros que inter-relacionam linguagem verbal com diferentes recursos visuais e sonoros na produção de sentidos.

A respeito do uso de recursos semióticos na produção textual, Nascimento et al. (2011) afirmam que não existem textos monomodais ou monossemióticos, uma vez que mesmo os textos em que predominam a linguagem verbal apresentam recursos visuais, como a tipografia e a formatação. Por essa razão, os autores enfatizam a importância de se considerar os fatores sociais e econômicos que permeiam os processos de desenvolvimento da escrita e da leitura. Estes fatores, segundo eles, assumem relevância ainda maior ao considerarmos as mudanças da sociedade atual. Sob este viés, para o desenvolvimento de uma postura ativa e crítica por parte do aluno, frente a tais mudanças, o ensino deve favorecer o desenvolvimento da competência comunicativa multimodal, envolvida no reconhecimento e uso de diferentes recursos multimodais.

Outro aspecto importante apontado pelos autores, é que tanto a linguagem verbal quanto a visual permitem a construção de representações do mundo, uma vez que por meio delas atribuímos papéis aos participantes representados (pessoas, objetos, instituições) e estabelecemos diferentes relações entre os participantes, bem como entre eles e o leitor, razão pela qual se faz necessário um olhar crítico sobre as diferentes formas de uso da linguagem. Assim, podemos sustentar que a análise dos diferentes recursos utilizados nas produções de linguagem nos dão pistas para entender como o 
autor compreende e representa a realidade. Nascimento et al. (2011, p. 548) destacam que é tarefa do professor "aprofundar seu conhecimento sobre essa abordagem ao texto multimodal e refletir sobre como viabilizar sua aplicação em sala de aula".

Em linha de pensamento similar, Lemke (2010) nos alerta que já faz muito tempo que as tecnologias de letramento não são tão simples e se diferenciam em muitos aspectos das práticas de leitura e escrita mais antigas (caneta, tinta e papel). Antes da era impressa, o letramento nunca esteve tão vinculado ao texto escrito. Na era digital, muitos gêneros têm atrelado texto escrito e imagens visuais de forma que tornam as referências entre eles essenciais para que possamos entendê-los. Assim, a autora arrisca afirmar que nenhuma tecnologia é uma ilha, quanto mais complexas se tornam, mais situadas são, em redes mais amplas e longas tal qual em outras práticas culturais. A exemplo de Rojo (2009) e de Nascimento et al. (2011), a autora enfatiza que esses assuntos devem ser encarados na escola, e salienta ainda que não podemos continuar ensinando letramentos da metade do século $X X$, ou meramente apresentar aos alunos letramentos mais avançados. O que Lemke (2010) defende, é que devemos ensiná-los a usar sabiamente os letramentos e esperar que se saiam melhor do que nós.

No que tange ao trabalho desenvolvido com a linguagem multimodal na escola, Oliveira (2013) salienta que apesar do uso intensivo da imagem em outros contextos, ainda não há sistematização suficiente para ação pedagógica. Assim, diversas correntes teóricas têm desenvolvido pesquisas com foco em práticas de (multi)letramento como instrumento que possa levar ao exercício da cidadania. Para que isso seja possível, a autora afirma ser necessário um trabalho efetivo com a multimodalidade, em outras palavras, é fundamental um estudo que ultrapasse os limites do código linguístico e que leve em conta as unidades semióticas como parte da produção de sentidos.

Considerando o exposto, procuramos em nossa proposta didática explorar as diferentes possibilidades que o gênero em foco traz para leitura, buscando enfatizar que a palavra tem seu significado potencializado quando 
acompanhada da imagem que, por sua vez, significa mais quando acompanhada da palavra (KRESS, 2010; KRESS; VAN LEEUWEN, 2001). Além disso, buscamos explorar os demais recursos sonoros e visuais usados para construção de sentidos no curta-metragem The Fantastic Flying Books of Mr. Morris Lessmore.

\section{Proposta didática: o gênero discursivo curta-metragem como instrumento para o processo de ensino e aprendizagem de LI}

A proposta didática destina-se a alunos do $9^{\circ}$ ano do Ensino Fundamental II e baseia-se no curtametragem "The Fantastic Flying Books of Mr. Morris Lessmore", inspirado pelo Furacão Katrina, pelo $O$ Mágico de $O z$ e pelo amor aos livros. Esse curta, uma alegoria sobre o poder curativo das histórias, foi vencedor do Oscar de Curta-Metragem de Animação

Figura 1 - The

Fantastic Flying Books

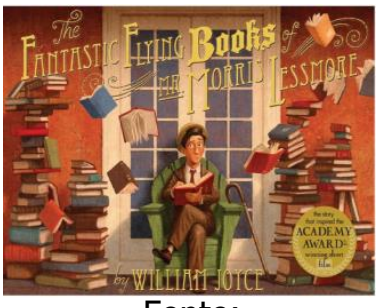

Fonte:

https://goo.gl/VaaQWQ de $2011^{3}$.

0 curta $^{4}$ foi escolhido por entendermos que a inserção do vídeo no espaço escolar pode promover um olhar diferente dos alunos para a prática da leitura bem como pela possibilidade de propiciar o letramento social, o qual acontece quando a escola se abre para os múltiplos letramentos, contribuindo para a formação de um estudante/espectador ativo, capaz de analisar, interpretar os textos fílmicos e integrar a recepção da obra ao seu mundo interior, conferindo-lhe sentidos (DAMINELLI, 2014).

Para a efetivação da proposta, optamos por um trabalho de leitura do vídeo a partir do uso de diferentes mídias (impressa e eletrônica). A fim de facilitar a visibilidade do trabalho proposto, organizamos as atividades conforme o quadro a seguir:

${ }^{3}$ Disponível em: <http://goo.gl/XOjihV>. Acesso em: 29 set. 2015.

${ }^{4}$ Disponível em: <https://goo.gl/VaaQWQ>. Acesso em: 29 set. 2015. 


\section{Quadro 1: Descrição da proposta}

Proposta didática: O gênero discursivo Curta-metragem como instrumento para o processo de ensino e aprendizagem de $L I$

Ano: $9^{\circ}$ ano do Ensino Fundamental II

Tempo de duração: 9 aulas

Etapa 1: Leitura de imagens: produção de inferências e de sentidos

Aulas 1, 2 e 3:

- Análise e descrição oral de imagens de cenas do curta-metragem;

- Exploração de elementos semióticos das imagens $5^{5}$ : produção escrita de uma sequência descritiva, em grupos, com o foco na multissemiose presente nas imagens;

- Apresentação oral da produção escrita.

Etapa 2: Estudo do curta-metragem: produção de sentidos a partir do contexto de produção

Aulas 3, 4, 5 e 6 :

- Estudo sobre o contexto de produção do curta-metragem;

- Apresentação do curta-metragem;

- Descrição de sentimentos provocados pela trilha sonora do curta-metragem;

- Compartilhamento dos sentimentos evocados pela trilha sonora e produção de um gráfico representativo de tais sentimentos;

- Retomada dos sentidos produzidos pelos alunos na etapa 1 , comparando-os a fim de aceitá-los ou refutá-los, com base na exibição do vídeo;

- Discussão sobre as possíveis temáticas abordadas no curta-metragem.

Etapa 3: The Fantastic Flying Books of Mr. Morris Lessmore: estabelecendo relações entre o texto verbal e não verbal:

Aulas 7, 8 e 9:

- Estudo do contexto de produção do livro The Fantastic Flying Books of Mr. Morris Lessmore;

- Estudo da linguagem verbal do livro The Fantastic Flying Books of Mr. Morris Lessmore;

- Jogo quebra-cabeça: montar a capa do livro The Fantastic Flying Books of Mr. Morris Lessmore;

- Jogo de associação: ligar o texto verbal de cada página do livro The Fantastic Flying Books of Mr. Morris Lessmore às imagens correspondentes;

- Atividade de conclusão da proposta: retomada oral sobre as diferentes etapas do trabalho acerca do curta-metragem e do livro The Fantastic Flying Books of Mr. Morris Lessmore, com foco nos elementos multissemióticos e nos sentidos produzidos pelos alunos.

Fonte: As próprias autoras.

\section{Descrição das atividades}

\section{Etapa 1}

\section{Leitura de imagens: produção de inferências e de sentidos}

\footnotetext{
${ }^{5}$ Para maior detalhamento sobre o trabalho com imagens, sugerimos a leitura de Lara (2011).
} 
Objetivos:entrar em contato com a proposta de trabalho; interessar-se pelo assunto; ler um mesmo texto de diferentes formas; refletir sobre as possibilidades de leitura de um texto imagético.

1) Projeção das imagens que seguem, pelo print da tela do curta-metragem, para que sejam descritas pelos alunos. Será por meio desta descrição que o professor identificará quais as possíveis leituras e produções de sentido realizadas por eles, tendo em vista o conhecimento de mundo dos estudantes.

Quadro 2: Print de algumas imagens do curta-metragem

\begin{tabular}{|c|c|}
\hline The Fantastic Flying Books 1 (0:58) & The Fantastic Flying Books 2 (2:48) \\
\hline The Fantastic Flying Books3 (4:02) & The Fantastic Flying Books4 (5:28) \\
\hline The Fantastic Flying Books5 (6:01) & The Fantastic \\
\hline The Fantastic Flying Books 7 (9:17) & The Fantastic Flying Books 8 (11:02) \\
\hline
\end{tabular}


The Fantastic Flying Books 9 (12:50)

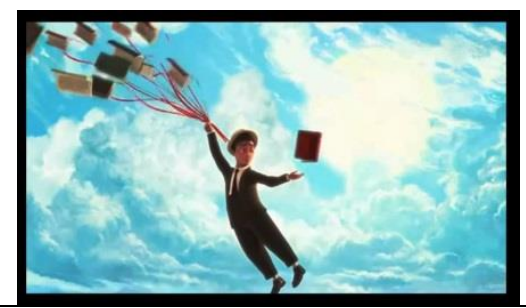

The Fantastic Flying Books 10 (13:31)

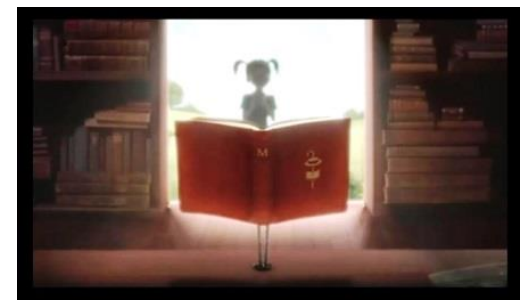

Fonte: <https://www.youtube.com/watch?v=Ad3CMri3hOs>. Acesso em: 29 set. 2015.

2) Exploração das imagens apresentadas na atividade 1. Para isso, indicamos as seguintes perguntas que podem ser feitas oralmente: i) What does the picture show? ii) What and where do the events happen? iii) Who is practicing the action? iv) What are people doing? v) What is happening? vi) What are the colors used? vii) What does their use indicate? viii) What is your opinion about the Picture? Assim, analisar, com base na descrição feita pelos alunos, a relevância do emprego das cores nas imagens. Por exemplo, o momento em que os personagens estão em preto e branco-representando a destruição e tristeza causadas pelo furacão e o poder curativo das histórias para aqueles que liam os livros doados para os abrigos. Esse poder é representado pela cor atribuída aos personagens ao receberem e lerem o livro.

3) Produção escrita de uma sequência descritiva, a partir da análise de imagens. Os alunos, em grupos, receberão duas imagens e realizarão a análise com foco em um dos possíveis elementos semióticos presentes nas imagens (cores, expressões faciais, objetos, formas, iluminação utilizada, os gestos, distanciamento, entre outros), conforme orientação do professor ${ }^{6}$. Com base na análise, produzirão, por escrito, uma sequência descritiva, em inglês, para cada imagem. Sugerimos a apresentação oral da sequência descritiva pelos alunos.

\section{Etapa 2}

\section{Estudo do curta-metragem: produção de sentidos a partir do contexto de produção}

\footnotetext{
6 Professor, sugerimos que os elementos semióticos a serem analisados se distribuam de acordo com a sua presença nas imagens, bem como atenda ao número de grupos da turma.
} 
Objetivos: entrar em contato com o gênero curta-metragem; expressar sentimentos; expressar diferentes percepções quanto aos efeitos de sentido, tendo em vista as imagens do vídeo; estabelecer relação entre o que foi realizado na Etapa 1 e a proposta da Etapa 2.

1) Estudo sobre o contexto de produção do curta-metragem. Os estudantes deverão fazer uma busca nainternet ${ }^{7}$, a fim de responderem às seguintes perguntas: i) Who produced the short film? ii) Who directed the short film? iii) When was the short film produced? iv) Where was the short film produced? $v$ ) What kinds of media were used to produce the film? vi) What is the film plot? vii) What inspired the film? viii) How is the short film described in, at least, three different sites? ix) How was the film received by the audience? Após a pesquisa, o grupo fará uma discussão sobre as respostas obtidas, destacando os aspectos que considerarem relevantes.

2) Apresentação do curta-metragem para possibilitar o primeiro contato com a história.

3) Estudo do vocabulário referente aos adjetivos que fazem parte da próxima atividade ${ }^{8}$.

4) Realização da atividade "How would you express your feelings about this short film from its songs?' (Anexo 1). Para isso, será necessária a reapresentação do curta-metragem.

5) Compartilhamento dos sentimentos evocados pela trilha sonora do curtametragem, conforme atividade "How would you express your feelings about this short film from its songs?"(Anexo 1). Sugerimos a produção de um gráfico, que pode ser feito no laboratório de informática da escola, com os dados obtidos a partir do resultado da turma.

\footnotetext{
7 Essa atividade poderá ser realizada no laboratório de informática da escola ou como tarefa de casa.

8 Adjetivos utilizados para a atividade sugerida. Disponível em: $<$ http://www.yourdictionary.com/index.php/pdf/articles/172.adjectivesfortonefeelingsemotions. pdf>. Acesso em: 29 set. 2015.
} 
6) Retomada dos sentidos produzidos pelos alunos na etapa 1, comparando-os a fim de aceitá-los ou refutá-los;

7) Discussão sobre as possíveis temáticas abordadas no curta-metragem. Consideramos relevante um aprofundamento sobre as seguintes possibilidades: Hurricane Katrina (2005) ${ }^{9}$; o papel da leitura nas sociedades grafocêntricas; vida x morte; trabalho e o filme $\mathrm{O}$ Mágico de Oz.

\section{Etapa 3}

\section{The Fantastic Flying Books of Mr. Morris Lessmore: estabelecendo relações entre o texto verbal e não verbal}

Objetivos: estudar o contexto de produção do livro The Fantastic Flying Books of Mr. Morris Lessmore; fazer a leitura do texto verbal do livro; identificar as imagens que correspondem ao texto verbal por meio de um jogo ${ }^{10}$; retomar as diferentes etapas desenvolvidas; realizar a atividade de conclusão da proposta.

1) Estudo do contexto de produção do livro. Indicamos que os estudantes façam uma busca na internet a fim de responderem às seguintes perguntas ${ }^{11}:$ i) Who wrote the book? ii) Who illustrated the book? iii) When was the book written? iv?)Who published the book? v) What is the edition language? vi) What literary award did the book receive? vii) Have you found anything else relevant about the book? If so, what is it? Após a busca, o grupo fará uma discussão sobre 0 que encontraram, destacando os aspectos que considerarem relevantes.

\footnotetext{
${ }^{9}$ Sugerimos que sejam mostrados o vídeo e o texto sobre o Furacão Katrina. Disponível em: <http://www.history.com/topics/hurricane-katrina>. Acesso em: 03 out. 2015. Ver anexo II.

${ }^{10}$ Há um comando no próprio jogo sobre como esta atividade deve ser realizada.

${ }^{11}$ Possíveis sites para obtenção das informações solicitadas: Disponível em: $<$ http://moonbotstudios.com/2013/01/the-fantastic-flyings-books-of-mr-morris-lessmorepicture-book.html>. Acesso em: 05 out. 2015; <http://www.goodreads.com/book/show/13083239-the-fantastic-flying-books-of-mr-morrislessmore>. Acesso em: 05 out. 2015.
} 
2) Jogo quebra-cabeça e jogo de associação. Essa atividade foi planejada para ser desenvolvida no laboratório de informática da escola. No caso das escolas públicas do Estado do Paraná, os laboratórios já estão habilitados para a realização do jogo proposto. Em outras escolas, alguns programas deverão ser baixados da internet para que o jogo funcione com êxito.

Quadro 3: Passos para o funcionamento do jogo

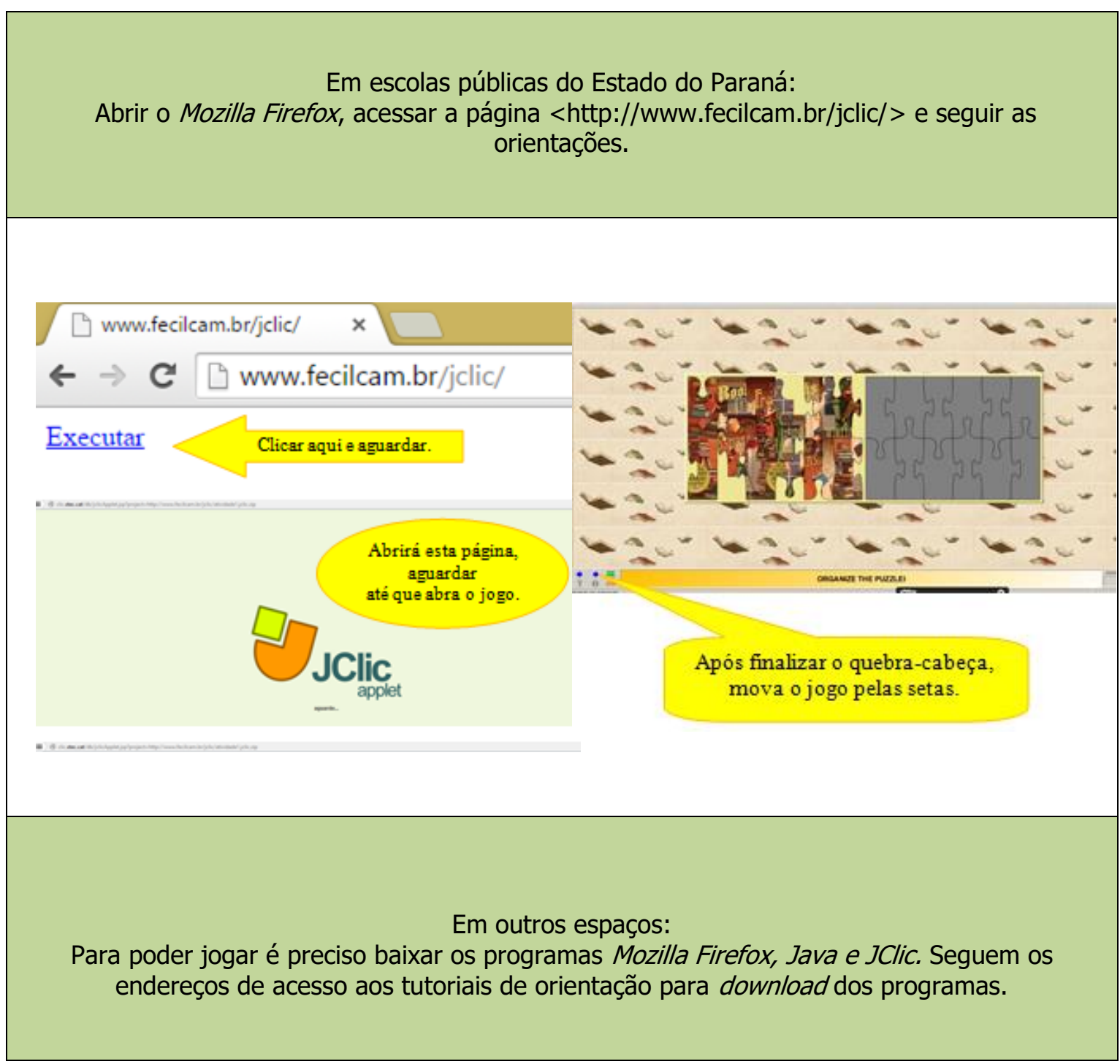


- Tutorial para o Mozilla Firefox: Disponível em:

<https://www.youtube.com/watch?v=26smofcTWpA>. Acesso em: 08 nov. 2015.

- Tutorial para o Java: Disponível em: <https://www.youtube.com/watch?v=JOms6CQRugY>. Acesso em: 08 nov. 2015.

- Tutorial para o JClic: Disponível em: <https://www.youtube.com/watch?v=ppzySpqv8j4>. Acesso em: 08 nov. 2015.

Depois dos programas instalados, abrir o Mozilla Firefox, acessar a página http://www.fecilcam.br/jclic/ e seguir as orientações, conforme ilustração abaixo.
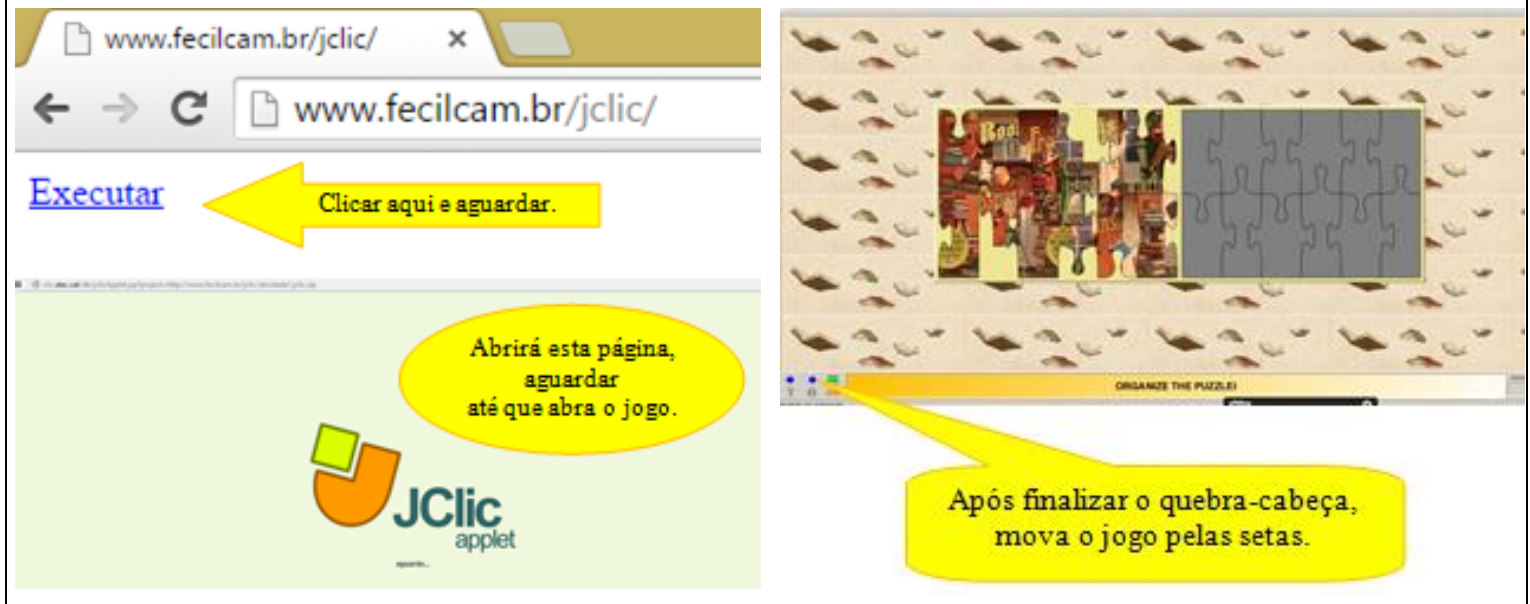

Fonte: As próprias autoras.

3) Conclusão da proposta: retomada oral sobre as diferentes etapas do trabalho acerca do curta-metragem e do livro The Fantastic Flying Books of Mr. Morris Lessmore, com foco nos elementos multissemióticos e nos sentidos produzidos pelos alunos. Além disso, os estudantes receberão a seguinte atividade que deverá ser realizada individualmente e, depois, discutida coletivamente:

Quadro 4: Atividade de retomada da proposta

You have studied a story with the same title in two different media. Read the information below and tick the box, which corresponds to the short film, to the book or to both.

\begin{tabular}{|l|c|c|c|}
\hline \multicolumn{1}{|c|}{ Information } & Short Film & Book & Both \\
\hline $\begin{array}{l}\text { The presence of narrative elements: place, time, } \\
\text { characters, etc. }\end{array}$ & & & $\sqrt{ }$ \\
\hline
\end{tabular}




\begin{tabular}{|c|c|c|c|}
\hline $\begin{array}{l}\text { Three phases of the narrative: before the hurricane, } \\
\text { during the hurricane, after the hurricane. }\end{array}$ & & & $\sqrt{ }$ \\
\hline $\begin{array}{l}\text { Story aesthetics: dichotomy between the colors black } \\
\text { and white. }\end{array}$ & & & $\sqrt{ }$ \\
\hline Presence of sound. & $\sqrt{ }$ & & \\
\hline Chronological sequence of the events. & & & $\sqrt{ }$ \\
\hline Absence of voice sound. & $\sqrt{ }$ & & \\
\hline Presence of music. & $\sqrt{ }$ & & \\
\hline Narrative in a full view. & $\sqrt{ }$ & & \\
\hline $\begin{array}{l}\text { Use of the key-scenes and suppression/agg/utination of } \\
\text { some moments. }\end{array}$ & & $\sqrt{ }$ & \\
\hline Spectator. & $\sqrt{ }$ & & \\
\hline Reader. & & & $\sqrt{ }$ \\
\hline $\begin{array}{l}\text { Ilustration (more details in the representation of the } \\
\text { characters and the scenarios). }\end{array}$ & $\sqrt{ }$ & & \\
\hline Linear events. & & & $\sqrt{ }$ \\
\hline Images and sound work in the creation of meaning. & $\sqrt{ }$ & & \\
\hline Images and text work in the creation of meaning. & & $\sqrt{ }$ & \\
\hline Image in movement. & $\sqrt{ }$ & & \\
\hline
\end{tabular}

Fonte: As próprias autoras. 


\section{Considerações finais}

Com base nas reflexões realizadas neste artigo e tendo em vista a crescente popularização dos meios digitais na contemporaneidade, salientamos que tem sido atribuído à escola o papel de melhorar a qualidade de participação dos alunos nas novas práticas letradas disponíveis. Para tanto, a escola precisa propiciar variadas experiências de leitura e produção de textos que contemplem diferentes gêneros circulantes no contexto das novas tecnologias. Além disso, deve promover a compreensão crítica e reflexiva a respeito das várias formas de construção dos discursos, bem como das representações de mundo engendradas por eles, daí a necessidade de se pensar novas formas de letramento.

Considerando este cenário, a proposta didática ora apresentada não teve o objetivo de esgotar as possibilidades de trabalho com o gênero curtametragem e com o próprio exemplar do gênero explorado - The Fantastic Flying Books of Mr. Morris Lessmore, tampouco de se fazer revolucionária. Todavia, buscamos desenvolver sugestões, dicas e atividades que proporcionem ao professor a exploração de aspectos multimodais e multissemióticos do vídeo/livro. Procuramos, ainda, construir uma proposta possível de ser implementada em contextos com acesso limitado a recursos tecnológicos, como sabemos que é o caso de muitas de nossas escolas públicas. Esperamos que o professor possa ampliar/adaptar esta proposta didática para seu contexto de ensino, além de inspirar-se para o desenvolvimento de outras propostas que apreciem diferentes gêneros inseridos no ambiente tecnológico.

\section{Referências}

BAKHTIN, Mikhail; VOLOSHINOV, Valentin. Estética da Criação Verbal. São Paulo: Martins Fontes, 1979/1992. 
CARMELO, Bruno. The Fantastic Flying Books Of Mr Morris Lessmore, vencedor do Oscar de melhor curta-metragem de animação em 2012, já pode ser conferido na Internet. 2012. Disponível em:

<http://www.adorocinema.com/noticias/filmes/noticia-100014/>. Acesso em: 29 set. 2015.

CASTELLS, Manuel. $A$ sociedade em rede. Tradução de Roneide Venancio Majer. São Paulo: Paz e Terra, 2000, v. 1.

CAZDEN, Courtney. et al. A pedagogy of multiliteracies: Designing social futures. Harvard Educational Review. Research Library: Spring, 1996, v. 1, p. 66.

HISTORY. Hurricane Katrina. 2015. Disponível em:

<http://www.history.com/topics/hurricane-katrina>. Acesso em: 04 out. 2015.

DAMINELLI, Silvane. Filmes legendados: perspectiva para o ensino de leitura em língua materna. 2014. 189f. Tese (Doutorado em Estudos da Tradução) Universidade Federal de Santa Catarina - UFSC, Florianópolis, 2014.

KRESS, Gunther. Multimodality: a social semiotic approach to contemporary communication. New York: Routledge, 2010.

KRESS, Gunther; VAN LEEUWEN, Theo. Multimodal discourse: The modes and media of contemporary communication. London: Arnold, 2001.

LARA, Glaucia Muniz Proença. A imagem como objeto de ensino. CASA (Cadernos de Semiótica Aplicada). [s. I.] [s. n], v. 9, n.1 p. 1-14, 2011.

LEMKE, Jay. Letramento metamidiático: transformando significados e mídias. Trabalhos em Linguística Aplicada, Campinas: [s. n], v. 49 (2), p. 455479, 2010.

NASCIMENTO, Roseli Gonçalves do; BEZERRA, Fábio Alexandre Silva; HEBERLE, Viviane Maria. Multiletramentos: iniciação à análise de imagens. Linguagem \& Ensino, Pelotas: [s. n], v. 14, n. 2, p. 529-552, 2011.

OLIVEIRA, Derli Machado de. Gêneros Multimodais e Multiletramentos: novas práticas de leitura na sala de aula. In: VI FÓRUM IDENTIDADES E ALTERIDADES II CONGRESSO NACIONAL EDUCAÇÃO E DIVERSIDADE, 2013, Itabaiana. Anais... Itabaiana: Anais do vi fórum - II CONED - Caderno de Resumos, 2013. p. 31-31.

PEREIRA, Cimar Azeredo. Acesso à internet e à Televisão e Posse de telefone Móvel Celular para Uso Pessoal. Disponível em:

<http://biblioteca.ibge.gov.br/visualizacao/livros/liv93373.pdf>. Acesso em: 29 set. 2015. 
ROJO, Roxane. Prólogo. In: ROJO, Roxane. Letramentos múltiplos, escola e inclusão social. São Paulo: Parábola Editorial, 2009, p. 7-13.

ROJO, Roxane; BARBOSA, Jacqueline. Hipermodernidade, multiletramentos e gêneros discursivos. 1. ed. São Paulo: Parábola Editorial, 2015.

ROJO, Roxane; MOURA, Eduardo. (Org.). Multiletramentos na escola. São Paulo: Parábola, 2012.

ROJO, Roxane; MOURA, Eduardo. Vidding: uma leitura subversiva do cânone. In: BUNZEN, Clécio; MENDONÇA, Márcia. (Org.). Múltiplas linguagens para o Ensino Médio. São Paulo: Parábola Editorial, 2013, p. 233-263. 


\section{Apêndice 1}

How would you express your feelings about this short film from its songs? How do they make you feel when you hear them? Choose an answer:

1. The introduction, Mr. Morris Lessmore writing
() Happy
() Bored a book

2. The beginning of the hurricane

( ) Worried

() Frightened

() Other(s)

3. The development
( ) Uncomfortable
( ) Comfortable
() Other(s)

4. The end of it

( ) Surprised

() Sad

() Other(s)

5. The new beginning after the hurricane

( ) Hopeful
( ) Excited
() Other(s)

6. The hope

() In love

( ) Angry

() Other(s)

7. When he arrives at the Fantastic Flying

( ) Brave book's house

( ) Disappointed

( ) Other(s)

8. The arriving

( ) Involved

() Attracted

( ) Other(s)

9. When he knows the house

( ) Anxious

() Calm

() Other(s)

10. He dancing with the books

( ) Amazed

() Foolish

() Other(s)

11. The beginning of the day, when he wakes up

( ) Nervous

( ) Animated

() Other(s)

12. The despair of the old book

() Scared

() Involved 


\begin{tabular}{|c|c|}
\hline & ( ) Other(s) \\
\hline 13. Its reconstruction surgery & $\begin{array}{l}\text { () Embarrassed } \\
\text { () Annoyed } \\
\text { () Other(s) }\end{array}$ \\
\hline 14.Mr. Lessmore travelling around his words & $\begin{array}{l}\text { () Horrified } \\
\text { ( ) Sarcastic } \\
\text { ( ) Other(s) }\end{array}$ \\
\hline 15. The old book reconstruction & $\begin{array}{l}\text { ( ) Enlightened } \\
\text { () Supportive } \\
\text { () Other(s) }\end{array}$ \\
\hline 16. The beginning of a new day & $\begin{array}{l}\text { () Fresh } \\
\text { () Angry } \\
\text { () Other(s) }\end{array}$ \\
\hline 17. The books donation by Mr. Lessmore & $\begin{array}{l}\text { ( ) Frustrated } \\
\text { () Kind } \\
\text { () Other(s) }\end{array}$ \\
\hline 18. His aging & $\begin{array}{l}\text { () Joyful } \\
\text { ( ) Resentful } \\
\text { () Other(s) }\end{array}$ \\
\hline 19. His death (rejuvenation) & $\begin{array}{l}\text { () Disbelieved } \\
\text { () Frustrated } \\
\text { () Other(s) }\end{array}$ \\
\hline $\begin{array}{l}\text { 20.A new person coming and a new restart of } \\
\text { life }\end{array}$ & $\begin{array}{l}\text { () Faithful } \\
\text { () Depressed } \\
\text { () Other(s) }\end{array}$ \\
\hline
\end{tabular}

Fonte: as próprias autoras 


\section{Anexo 1}

Esta atividade poderá ser realizada em grupos ou no coletivo, dependendo das condições da escola em termos de acesso à internet. No primeiro caso, a turma trabalhará no laboratório de informática. Conforme divisão do professor, cada grupo lerá o tópico que lhe couber para depois recontá-lo aos demais colegas da sala. Na página, é possível ter acesso a outras informações e mídias, como vídeos, por exemplo. No caso de optar pela segunda opção, o professor apresentará o texto em data show e fará uma leitura coletiva, pedindo para que os alunos apontem as informações mais relevantes em relação aos fatos abordados.

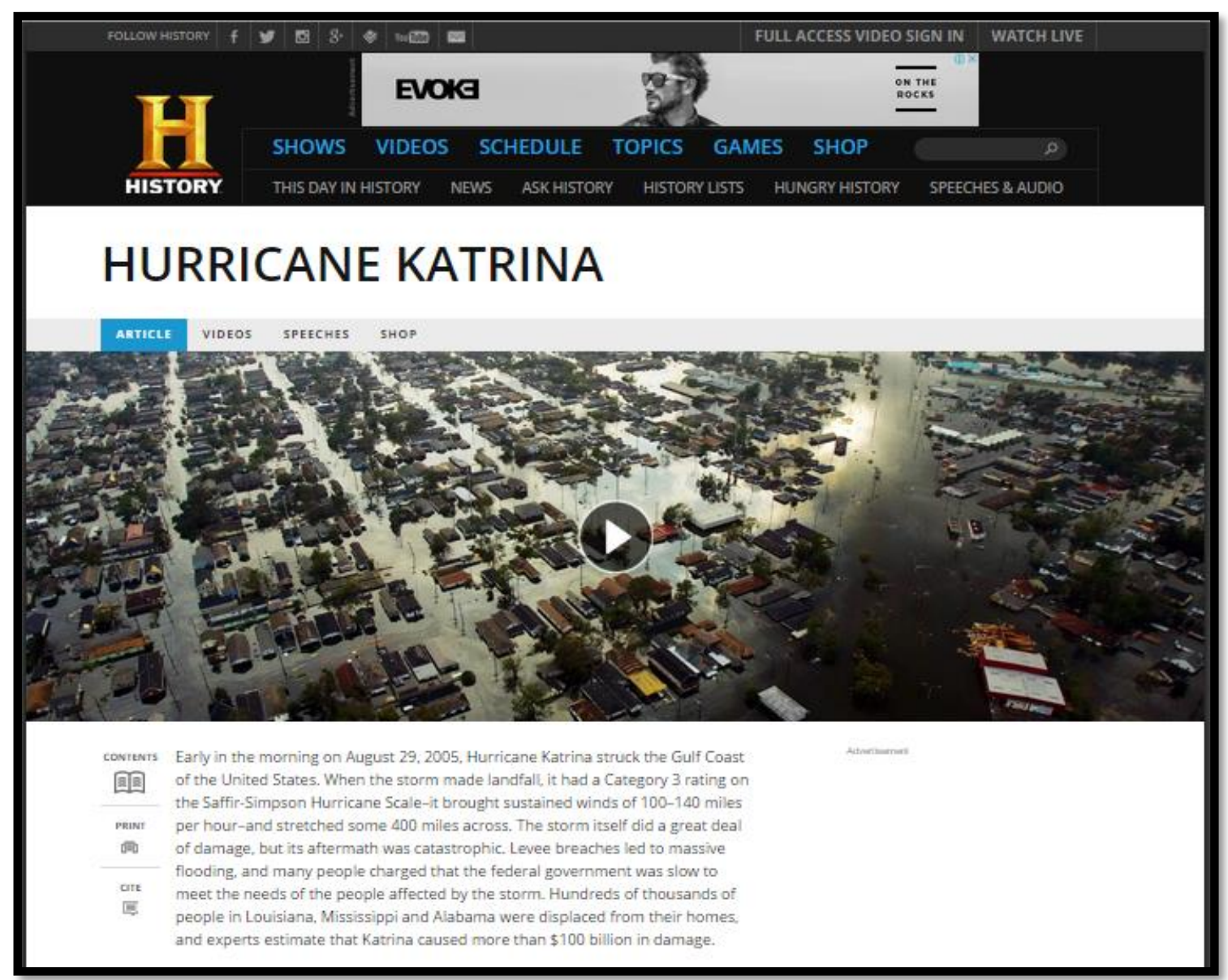

Fonte: <http://www.history.com/topics/hurricane-katrina>. Acesso em: 29 set. 2015. 